\title{
Immersion, authenticity and the theme park as social space: Experiencing the Wizarding World of Harry Potter
}

\author{
Abby Waysdorf and Dr. Stijn Reijnders
}

\begin{abstract}
This article examines the visitor experience of The Wizarding World of Harry Potter (WWOHP) theme park at Universal Studios Orlando. The park is hugely popular and has been embraced by the series' devoted but critical fanbase. Prior research on theme parks has generally focused on critiques of their form, leading to a limited understanding of their appeal. This article asks how fan-visitors interpret this simulated environment, and what leads them to embrace it. It does this with an ethnographic approach, utilizing in-depth interviews with 15 visitors combined with participant observation. We show how WWOHP is understood by its visitors as an adaptation of the series into physical space, via the medium of the theme park, and how the visitor's experience is shaped through use of ironic imagination. In doing so, we present a new understanding of the immersive media experience of theme parks.
\end{abstract}

Keywords: fandom, theme parks, Harry Potter, immersion, tourism Word Count (including abstract, references, and keywords): 7989 
"That's what WWoHP is about. Living it. Being transported to that world and living a day, or a night, there. And that will be completely and truly MAGICAL," reads a Tumblr post by user 'niallgirlalmighty', as part of her description of the Wizarding World of Harry Potter (henceforth WWOHP) in Universal Studios Orlando and Universal Studios Islands of Adventure. This post joins many similar ones by fans of the Harry Potter series, who have been flooding to the parks since the first WWOHP opened in 2010. The parks feature not only rides, some in immersive 3-D, but complete recreations of fictional locations from the Harry Potter series - the village of Hogsmeade, site of the central location of the Hogwarts School of Witchcraft and Wizardry, and the London wizard-only shopping district of Diagon Alley, each with architecture, shops, and restaurants featuring products and imagery from the series. Its success has lead Universal Studios to open WWOHP areas in both its Osaka and Hollywood parks. WWOHP exemplifies a push in the industry towards more immersive theming around known narrative worlds, going beyond rides and souvenirs into full, complete environments promising immersion into a favorite text.

Visiting theme parks has been a popular pastime since they started appearing in the mid 1950s, yet there is still little understanding of what makes them so. Research has largely focused on a critique of their form, particularly from a postmodern perspective that focuses on the role of simulation in an image-focused society (Eco 1986, Sorkin 1992, Baudrillard 1994, Rodaway 1994, Gottdiener 2001, Bryman 2004), overlooking the visitors themselves and how they make meaning out of such simulated environments. 
This means there is only a limited understanding of why theme parks actually appeal to the millions who enjoy them.

We believe that in order to understand the success and impact of WWOHP, and indeed theme parks in general, it is necessary to work from the perspectives of visitors. How do visitors interpret this simulated environment, and what leads them to embrace it in the way that niallgirlalmighty and others have embraced WWOHP? By answering these questions we hope to not only present a deeper understanding of the theme park experience, but also to shed light on the complex interactions of fandom, commerce, and physical space in the $21^{\text {st }}$ century.

Our empirical investigation is based on interviews with 15 Harry Potter fans that have visited WWOHP, complemented with participatory observation at the park. We suggest that the success of WWOHP can be credited to its understanding as an authentic adaptation of the Harry Potter story-world, a place where Harry Potter fans can employ their ironic imagination (Saler 2012) and experience the story-world in an embodied manner. The implications of these findings will be explored by first discussing the nature of theme parks as a form or medium (Clavé 2007), one that potentially enhances the immersive aspect of contemporary storytelling and use of the "ironic imagination" (Ryan 2001, Saler 2012). Following this, we analyze the interviews in the context of our observations in the park, presenting a new understanding of how simulated places are understood, experienced, and appreciated today.

\section{Understanding the Wizarding World}


In most intellectual traditions, the theme park is seen negatively. Eco (1986) is discomfited by the idea that "Disneyland tells us that technology can give us more reality than nature can" (44), while Sorkin suggests that "a trip to Disneyland substitutes for a trip to Norway or Japan" and in choosing Disney over these locations the tourist "has preferred the simulation to the reality" $(1992,216)$. The theme park from this perspective dangerously destabilizes the separation between reality and unreality, especially for unsophisticated tourists who seemingly "prefer" the fake. They are also seen as generic, lowest-common-denominator entertainments that fail to fully represent what they are recreating in order to have mass appeal. Their success points to a postmodern preference for simulation, safety, and entertainment over the "real" experience of landscapes and environments, and the flattening of everything in post-modern life to mass-produced images.

Even those who take a positive view towards popular culture frequently dismiss theme parks. Aden (1999) contrasted the experience at the filming location for the film Field of Dreams to that of being at an amusement or theme park, stating that "fans treat the field as something special rather than as an ordinary amusement park-type site." (228) The lack of entrance fee and ability to wander create, to Aden, "a special place full of communitas not found anywhere in the mundane, consumerist habitas" $(1999,234)$. Theme parks, with their boundaries and explicit commercial purpose, are contrasted with this purer, non-commoditized location. Similarly, Hills' concept of "cult geography" is defined as "fan attachment to non-commodified space, or at the very least, to space/place which has been indirectly or unintentionally commodified so that the fan's experience of this space is not commercially constructed." $(2002,151)$ The commodified space of the 
theme park is compared to the non-commercial, individual tour of $X$-Files filming locations in Vancouver, considered a true space of cult geography as the experience is constructed through the fan's meaning-making processes rather than the media or tourist industry. Both Aden's Field of Dreams site and Hills' Vancouver also point to a valorizing of "real" locations connected to popular culture. As is discussed in regards to film tourism (Couldry 2000, Beeton 2005, Brooker 2007, Reijnders 2011,), the actual place of filming is thought to have a powerful aura that fans seek out in order to truly connect with a favorite narrative.

At the heart of all these critiques is the idea that theme parks are inauthentic spaces - either in that, as artificial landscapes, they substitute for "real" experiences of place or, because of their lack of connection to actual filming and/or their commercial purpose and design, they are unsuitable for authentic engagement with favorite texts or fandoms.

It is possible, however, to think of theme parks differently. Lukas (2007) argues that themed environments have their own form of authenticity - one based on their multisensory aspects. A themed environment becomes authentic when it "is sensory available" (Lukas 2007, 82). Those visiting know it is a simulation, but it becomes an authentic one when it feels correct on all sensory levels. . Similarly, Clavé stresses that theme parks should be thought of as "cultural creations equivalent to a painting, a photograph or a film.” $(2007,178)$ This is not to say that they aren't commercial, corporate, and geared towards consumption - but that they should also be evaluated as creative productions. Theme parks are "a place of fiction that bases its existence on the materialization of a fantastic narration through shapes, volumes and performances." 
(2007, 178) Rather than examples of society's preference for sanitized versions of reality, they are specific places in which fantasies, mythologies, and cultural icons can be enacted and played with. This engagement is heavily visual, but by no means exclusively so, as theme parks and rides also present a multisensory experience not utilized in other media. As with other art forms, they are meant to be an interpretation of a story, and are no more or less challenging to the idea of reality.

Physical separation is a key characteristic that makes them effective as a cultural form: "[t]he 'vocation' of parks is to be worlds apart." (Clavé 2007, 193) Combined with the fantastic narration of theming, the visitor is encouraged to experience them as not the same place as outside. The park functions as an artwork, and "as a real object inscribed in space and time, the work of art is in the world, but as a virtual object that creates its own space and time, it is not of the world" (Ryan 2001, 41). Within the enclosed space, the visitor is encouraged to engage with the fictionality of the theme(s), to pretend and imagine on a bodily level while inside.

The majority of used narratives are, however, known from outside the park. Davis (1996) explains theme parks as a version of "media convergence" before this term was in vogue: a place to provide new interpretations and promotions of the same media text, utilizing different senses in order to provoke interest. As Mitrasinovic (2006) discusses, this is the model pioneered by the Disney parks, which utilize familiar landscape archetypes such as "small-town America" and combine them with the familiar brands of the Disney media empire. Koren-kuik (2014) describes them as "spatial narratives" that present a different form of engagement with the familiar characters and worlds of Disney, requiring physical presence and corporeal senses. What the park offers 
is the chance to physically interact with characters and narratives that are well-loved, made all the more powerful for the long history of Disney media, its existing cultural meanings, and the interaction of different Disney texts with each other. The Disney model of design and cross-marketing is the archetype on which cotemporary theme parks are based (Mitrasinovic 2006), including Universal Studios. Its concept is based around film in general, utilizing popular "blockbuster" narratives like Jurassic Park and Marvel superheroes in its rides and environments. It is this tradition that WWOHP follows in.

Compared to other theme parks, including other areas within Universal Studios, WWOHP takes a more holistic approach to its theming. It is presented as a complete reconstruction of locations from the Harry Potter series, rather than an environment that uses elements from it in order to create a general sense of fantasy. Specifically, it reproduces these locations, the village of Hogsmeade and the urban neighborhood of Diagon Alley, as they appear in the Harry Potter film series, with a sense of scale that match the proportions of an English urban environment. In doing so, it comes closer to the idea of simulation as utilized in media and game studies, where it is seen as a key aspect of new media storytelling and artistic technologies. A simulation creates a sense of immersion: feeling, through the medium, that the audience member is part of the artistic or narrative world (Huhtamo 1995, Darley 2000, Ryan 2001, Grau 2003). According to Huhtamo, "the quest for immersive experience is a cultural topos, which has been activated — and even fabricated — now and again in culturally and ideologically specific circumstances." $(1995,160)$

This search for immersive experience is frequently applied in theme parks to the simulation ride (Huhtamo 1995, Darley 2000, Balides 2003), but we can also think of the 
entirety of the theme park experience in this fashion, They are enclosed spaces in which the visitor enters to feel immersed in fiction. Ryan argues that "the Disneyland tourist, beloved scapegoat of cultural critics, deserves credit for the ability to appreciate the art that goes into the production of the fake." $(2001,41)$. By this, Ryan refers to enjoying the sense of immersion in a fictional story-world and the appreciation of the skill that makes it believable. She argues that this is one of the great pleasures of narrative, a "fundamental and timeless dimension of aesthetic experience" (ibid.). It is what gives fiction its enduring place: the framework to imagine potentialities and alternatives, to explore what could be.

Ryan's concept of involvement and immersion in narrative worlds is further elaborated by Saler (2012). Rather than immersion through technology, Saler stresses immersion through imagination. He investigates the broader cultural construction of what he terms "virtual worlds," "acknowledged imaginary spaces that are communally inhabited for prolonged periods of time by rational individuals" (2012, 7). To Saler, a story-world becomes virtual when it is adopted and discussed by many individuals, who group together in order to explore and fill in its details and make it more 'real'. The storyworld becomes immersive because it feels inhabitable - as detailed as the 'real world' and shared with others as a sort of imaginary habitus.

It is this experience that Universal Studios attempts to reproduce at WWOHP through the medium of the theme park, utilizing its characteristics in order to make physical a process that Saler depicted as cerebral and communal. But how is it received by those who visit? It is to this question that we now turn. 


\section{Studying the Wizarding World}

Research for this study was conducted in the spirit of grounded theory as described by Charmaz (2006), beginning from an open-ended desire to investigate the fan experience of WWOHP and undergoing theoretical refinement throughout the research process. We focused on fans due to the connection they have with the narrative world being represented, one that makes them both likely to desire a connection but also be critical of how it is produced. It is primarily based on interviews with park attendees, complimented by participatory observation in the parks. Interviews were selected as the primary method in order to focus on how the fans themselves interpret the experience of WWOHP. Initial fieldwork and participatory observation was conducted at WWOHP Orlando in late December 2014, the first winter holiday since the opening of Diagon Alley, as this is a peak time for theme park visitation and the highly-anticipated expansion attracted many fans, even if they had already been. Participatory observation was over three days, with the researcher spending approximately 10 hours per day in the Harry Potter areas of the two Universal Studios parks, and consisted primarily of experiencing the park as a visitor, but also observing other visitors and their interactions with the park. While privately owned, theme parks are largely treated as public space (Gottdiener 2001, Mitrasinovic 2006), and observations were made in an unobtrusive manner without references that could identify individuals or specific social groups.

The majority of interviewees were met in WWOHP at the time of fieldwork, and were approached based on visible fan behavior in the park such as attire, reactions to certain attractions, or reciting book or film dialogue. While subjective, such cues serve as 
a way to identify oneself publicly as a fan to other fans, which is frequently desired at WWOHP. After the initial introduction in the park they were contacted via email to further explain the research and set up an interview, to which thirteen then agreed to be interviewed. Two interviewees were recruited via social networking site Tumblr, where fans share posts about the Harry Potter series and visits to the parks, in order to both reach saturation and to ensure perspectives from fans involved in the online participatory communities that are emblematic of contemporary fandom. The interviews were conducted via Skype several weeks after the initial trip. While this approach sacrificed the immediacy and physical presence of an on-site or face-to-face interview, it allowed for greater comfort for the interviewees as they could set their own time and place to be interviewed, away from the crowds and noise of the park itself and without sacrificing any time out of their holiday. This also led to a more reflective attitude, as they had time to process their experience at the park and to put it into the narrative they wished to share. Interviews lasted approximately 30 to 75 minutes and were semi-structured and open-ended. This allowed for a comparison between interviewees on specific aspects of the WWOHP experience, but also permitted following up on particular themes as they emerged. Questions addressed the existing relationship to the Harry Potter series, the reasons for wanting to visit WWOHP, expectations for the visit, activities and emotions while there, standout memories from the park, purchases made while there, and finally, their feelings about the park at the time of the interview. In total, fifteen visitors were interviewed, three from Canada, one from China, and the rest from the United States, with ages ranging from 17 to 44, with the majority in their twenties and early thirties. Thirteen interviewees were female and two were male. All interviewees were informed of 
the purpose of the research before their interview, and have been given pseudonyms to further protect their anonymity.

Full transcripts of the interviews and fieldnotes were coded and analyzed in a qualitative, thematic matter, first by several readings of the transcripts and fieldnotes, followed by coding in Atlas.ti, looking to determine specific themes, commonalities, and differences within the fan experience at WWOHP. From this analysis we have developed our understanding of the park experience, which will be detailed in the following sections.

\title{
Experiencing the Wizarding World
}

\author{
Locating Authenticity in the Theme Park
}

No movie filming has taken place at WWOHP. It is also far away from the setting

of the books, which has its own tourist industry based around the "original" landscapes of the series (Lee 2012). Nor does it boast relics from production, as is the case with popular culture exhibits in museums and elsewhere (Booth 2015). However, most of the interviewees still found visiting to be a powerful experience that connected them with the Harry Potter narrative world:

It's so fantastic there and it's just, it's like my favorite book come to life, and...like, I love this. Like, this is awesome, this is home, like I, I felt like, I had come home to some part of like, the small part of me that wishes more than anything that I could've entered that world, and that part of me feels more at peace now. (Maggie, 21, American) 
Maggie was not alone in discussing the park in terms of "finally" entering the story-world or even being in some way "home". Despite being a theme park in Orlando, it can still invoke an authentic sense of 'being there.' If we think of the park as a cultural creation or medium, it opens up the potential for a legitimate encounter with the story-world. The park is accepted as a valid adaptation.

This acceptance of WWOHP was credited to a few main factors. For several interviewees, the (perceived) involvement of Harry Potter series author J.K. Rowling was important:

I heard J.K. Rowling actually had say in everything, saying yes, that can be done, and no, that can't. So I think...the fact that she had a hand in bringing her creation to life, and has such high standards, I think that helped. (Circe, 29, American)

Authenticity for these fans is based on the figure of Rowling and her approval of the park. As the series' "brand guardian" (Gunelius 2008), her approval gives the park a sense of legitimacy. If something is there, then it is approved, and the experience is likely to be a good one if she signed off on it.

Most mentioned, however, was the amount of detail from the series present in the park:

Everything is perfect, it's really like you are there, it's exactly how it is described in the books, and it looks even cooler than it does in the movies, because in the movies - you know what I'm talking about: "Wait, that, what was that back there behind him?" and now you really can look at it, and having been to the actual set in London and then to the Wizarding World in Florida I can say it is so much more detailed, like they really went all out. (Jen, 30, American)

As Jen discusses, the amount and specificity of the details in WWOHP were considered crucial to its sense of realism. That it is 'exactly described' as it is in the books, visually matches the films, and provides more details than watching said films or even touring the set makes it feel that she is 'really' there. Interviewees regularly mentioned the level of 
detail as one of the things they most enjoyed about WWOHP, especially the "smaller" details that they felt might have been easily overlooked. They coalesced into a sense that this was a realistic depiction of the narrative world, one that held true to the image they had formed from years of familiarity. It therefore lived up to the ideal of the theme park an environment where a cultural fantasy can be engaged with in a multi-sensory way.

For many, it does this so well that that other theme parks are seen as inferior.:

The little details $[\ldots]$ make it feel like a real experience, not like a theme park. (Dan, 33, American)

The other theme parks are like watching TV about Europe, where the Wizarding World is being in Europe. It's just two different planes of comparison. (James, 44, American)

For Dan and James, WWOHP feels more sensorily authentic than other theme parks. WWOHP's detail - from the signs in shops to the British-style food and drink - create a sense of specificity that in turn fosters a sense of immersion in and authenticity to the story-world, especially when compared to the caricatured theming of other parks (Mitrasinovic 2006). For these fans, it is no longer just a theme park, with all its negative connotations. Instead, it is an accurate adaptation of the Harry Potter story-world.

That the film series is an adaptation as well also provides an interesting comparison to locations of film tourism. While the film set, a tourist attraction outside of London, can boast props and the real place of filming, it has no more claim on being the real Diagon Alley or Hogsmeade than WWOHP. They are both interpretations of a space that first existed in the imagination, and can therefore both serve as "places of the imagination" (Reijnders 2011) that link the imaginary world and landscape to ours. The reproduction of imagined details into physical space gives it a convincing presence: 
They were exactly like they were in the movies. So, you just felt like you were actually there and you're like 'oh Harry and Hermione and Ron were here but they're not here now.' (Melissa, 21, Canadian)

This sense of being at the right place at a different time is one that is desired in other cases of film tourism, which "sustain cult fans' fantasies of 'entering' into the cult text." (Hills 2002, 151) As it is 'exactly' like it is in the movies, this fantasy is realized for Melissa - it is as if she is in the same space as Harry and his friends have been.

The existence of the story-world across multiple media means that the theme park is seen as simply another depiction. Its authenticity is judged on its own character as a medium - its ability to represent the story-world in physical space. Because it is accurate, whether the fan has the books or the films in mind, it feels not only valid, but good art.

\section{Embodiment and Immersion}

If, as Crouch argues, it is through embodiment - "a process of experiencing, making sense, knowing through practise as a sensual human subject in the world" (2000, 68 ) - that we gain a real sense of a place, then the visitor on some level gains a sense of Diagon Alley or Hogsmeade through visiting WWOHP. As an interviewee recalls:

My daughter said, "I just wanted to bottle the air." Because it smelled of sugar, and not the sickly carnival sugars, but, sugar! And, you know, and this place, you could hear as you passed the shop with the cauldrons you could hear kind of the bubbling and the mandrakes were having a screaming... (Daphne, 44, American)

In the multisensory aspects of the theme park the story-world is engaged with in an embodied and immersive manner. While theme parks are often dismissed as strictly visual (Rodaway, 1994), Daphne and her daughter show, echoing Lukas (2007), this is not the case. Tastes, smells, sounds, and physical movements that are part of the narrative 
world are experienced through the park. This gives them an embodied sense of a storyworld that, while familiar, was previously only cerebral or audiovisual. Once the park's simulation is accepted as authentic, the visitor feels as if they are having a genuine encounter with the narrative world.

The layout of WWOHP encourages this. If the theme park is understood as a setaside place in which to engage with the imagination instead of everyday life, WWOHP extends further this by separating the Harry Potter sections from the rest of Universal Studios. It is entered through either a gate (Hogsmeade) or a "London" building façade that hides the "magical" part from view (the newer Diagon Alley), with a dramatic reveal as the visitor fully enters. This physical separation from the rest of the park is similar to the series' separation of "muggle" and "magical" societies and adds another layer of encouragement for the visitors to feel as they have entered another world. This is an emotional experience for many:

You just walk in and you see the Alley, it's just ... it made me want to cry. I was so excited, and so happy. It was just so overwhelming. (Elle, 17, American)

There are many such reports of amazement and tears at stepping into Diagon Alley for the first time. It is as if their dream, that they have received the letter of admission to Hogwarts that allows them to enter magical society, has come true. Visitors are encouraged to think of themselves as leaving their mundane existence behind them, just as Harry did.

The series means a great deal to its fans. They have long wanted to inhabit the narrative world, in some cases for much of their lives. This existing desire shapes the way they interact with the park and its attractions: 
I just wanted to ride the train. I would have been happy if it was just like, you could see Orlando through the window, but they have, like, a scene that goes by, and that's so cool. But it was just cool just to sit in the compartment and have that experience like going to Hogwarts and then coming back. (Hanna, 26, American)

The series has been important for much of Hanna's life and she has long dreamed of riding the Hogwarts Express, the train that takes magical students from London's Kings Cross Station to Hogsmeade. WWOHP uses a version of this train to connect the two WWOHP parks, entered through replicas of the two train stations and featuring short films outside the train's "windows" depicting the journey that the rider is imaginatively embarking on. While the ride version differs from how the train is described in the books and films, it is enough like its description that, combined with her existing wish to travel to Hogwarts and the immersive environment of the park, she felt 'like' she was having the experience. Saler (2012) refers to this as "ironic imagination," a "double consciousness" that allows the (modern) subject to be emotionally invested in and contemplative about a fictional world, while maintaining the knowledge that it is fictional. While Saler applied this to imagining and discussing a story-world, without the physical component, it is equally applicable here. Those who participate gain a sense of how it would feel if the story-world was not fiction: but they never lose sight of the fact that it is. Rather, they play with the idea that for a brief moment the lines between fiction and reality blur, a pleasurable pretense made all the more so by the effort they feel the park puts into the illusion. That WWOHP recreates story locations that don't otherwise exist also contributes to this exercise of the ironic imagination. The visitor knows that they are not actually in Diagon Alley or Hogsmeade, but there is no more "real" version, 
and it is a physical experience with all the cultural markers of reality. This makes it a convincing pretense, one that matches the existing imagination with physical sensation.

The train is not the only ride found in WWOHP. In addition to the child-friendly roller coaster Flight of the Hippogriff and the thrilling Dragon Challenge, both found in the Hogsmeade section and re-themed from the area's prior incarnation as Merlinwood, each WWOHP area boasts a modern a simulation ride. In Hogsmeade it is themed around the Hogwarts school, with the one in Diagon Alley themed around the Gringotts bank. Both utilize a combination of screens, 3-D projections, props, and movement to create a sense of kinetic immersion in the rides' story, and feature heavily decorated and narrativized areas for waiting in line. Both were praised by the interviewees. However, when discussing their favorite parts of the park, the actual experience of riding was rarely mentioned. Instead, it was the experience of the environment - both the detailed queues of Hogwarts and Gringotts and outer areas of Diagon Alley and Hogsmeade - that were brought up.

It is in these areas that WWOHP most matches the "virtual world" of the Harry Potter series that fans already mentally inhabit. While the rides are appreciated, they are too controlled to feel inhabitable. Within the broader environment, however, there is a much stronger sense of agency. Laid out as curving, intersecting city streets, with several potential directions for movement, WWOHP is a scripted space rather than a set one (Klein 1999). The visitors can take as much time as they want within it and, once past the entrance, wander in whichever direction they choose, similar to how Aden (1999) described the utopian Field of Dreams site. Scripted spaces create a sense of narrative centered around the walker, one with the illusion of agency (Klein 1999). Compared to 
how narrative agency is theorized within computer simulations (Murray 1997, Ryan 2001), however, it is minor, confined to activities like walking, eating, and shopping. Rather than controlling the narrative direction, the visitor to WWOHP is cast as an "ordinary" witch or wizard visiting the location. As the narrative world already has meaning and presence, this is enough.

WWOHP is a frequent site of cosplay, dressing up and embodying characters from the story-world, and some create a character for themselves while there:

So, we actually took a few minutes, my daughter and I, and we figured it out. My husband is Teddy, that is why she has the blue hair. And I am the daughter of Bill and Fleur, that is why [son] Ben has the red Weasley hair. (Daphne, 44, American)

At the park I'm usually a Death Eater or a Slytherin student. (Circe, 29, American) The idea of the park as a place to pretend encourages this use of cosplay - of fully embracing the idea that you are part of the world. A sense of agency in the narrative world encourages the idea of "as if." If the magical world was real, they would do these kind of things in it. They can (ironically) imagine that they are witches and wizards themselves, and the embodied physical sensations like movement, taste, and smell create an even stronger knowledge of the world.

Much of this embodied experience is built around consumption, but consumption filtered through the idea of "as if." The shops and products available frequently play important roles in the series. Being "able" to shop in WWOHP therefore also contributes to the illusion of "actually being there":

It literally is like you are in that shop. [...] It was just really cool, like I can't even believe I'm shopping in Honeydukes right now. (Hanna, 26, American)

Shopping is an immersive, imaginative act, one that connects Hanna to the story-world. She can visit the same candy shop that Harry and his friends visited throughout their time 
at Hogwarts, and purchase what she would if she was a witch. The stores are distinct, with different specialties that are frequently "diagetic expansions" as described by Mittell (2014): products from the series, or products that could be from the series (like shirts advertising in-universe sports teams). This creates a more realistic, but also more touristic, sense of place:

Like you are just vacationing in Diagon Alley, and then occasionally popping over to Hogsmeade, like it really did, because there is so much going on, there is so much to do, and it's just so cool, and it was really like vacationing... in... the Wizarding World. (Jen, 30, American)

When at WWOHP, visitors do what would if they were visiting any other urban tourist destination: they buy things, they wander the streets, get something to eat or drink, perhaps see a performance or people-watch. These can all be done convincingly, with "local delicacies" like butterbeer and exclusive souvenirs, in a way that adheres to the narrative memories and details of the Harry Potter series.

WWOHP is a massive success for Universal Studios. This popularity means that there are always many other people in attendance, which is something that visitors must navigate. It is interesting, however, that not every interviewee considered the crowds or lines a negative part of their experience:

A lot of times we'll just go and sit on a stairwell or something and you just watched people going around, or witches and wizards going and doing their things. And just kind of pretending, that "Oh, maybe I am just hanging out in Diagon Alley and having an ice cream right now." It's just fun, it's total wish fulfillment. (Dan, 33, American)

Other people create the sense that WWOHP is a lively and living space, much as the locations are in the series. It becomes a place to "hang out" rather than a place to pass through. Many interviewees spent entire days in the WWOHP section. The visitor takes on the role not only of a witch or wizard, but of an urban flâneur - strolling the streets 
and observing the other inhabitants of the city (who are also fellow characters in the story). To complete the sense of immersion, the space must be occupied.

The Social (and Fan) Space of Harry Potter

As testified by the interviews, another significance of others occupying the space derives from the sense that they were also there for Harry Potter:

For the most part a lot of people that were there, they really enjoyed and loved the Harry Potter series. And so it was kind of like this, all time, 24/7 nerd convention inside there. And so you could sit there and freak out about a T-shirt because it was awesome and it was your house, and nobody would be like 'oh my god that person is really weird.' (Maggie, 21, American)

Maggie sees the space as a Harry Potter environment in which she can "geek out" about the series without feeling self-conscious. Rather than simply connecting to one's individual fandom, visiting became a way of performing it publically and connecting to others who felt the same way. Research on fan conventions (Jenkins 1992, Bacon-Smith 1992, Booth and Kelly 2013, Geraghty 2014) discusses a similar sense of connection to fandom at large. In these spaces, fans feel they can 'be themselves' and embrace the 'nerdy' interests that they feel they must hide elsewhere. Similarly, at WWOHP fans felt as if they could indulge their fandom in a way they couldn't in everyday life.

The assumed shared interest in the series often creates a sense of fellowship among the visitors, at least among those exhibiting fannish appearance and behavior:

It was just really cool to have that kind of camaraderie throughout all spans of life. 'cause I mean, you could live across the world and we could both be in the same house, and we're like "Slytherin, what's up?" and you have that connection now with somebody that you had no idea who they were five seconds before. So it's really cool, it's like a giant family. (Circe, 29, American) 
For Circe, a Florida resident who regularly visits WWOHP, the other visitors to the park are not anonymous strangers - they are other Harry Potter fans that identify with the series as she does, indicated by fan behavior like dressing up or showing knowledge of the series. The connection she has with the park's other inhabitants makes it feel welcoming and special. Being in the park not only means being surrounded by the narrative world, but being surrounded by this community. Contrary to Aden, what this suggests is that WWOHP is felt as a place of communitas as Turner (1977) would describe it. Entering the WWOHP area means that a fan becomes part of the 'giant family' of fellow Harry Potter fans occupying the space, no matter their status outside the park, with the accompanying freedom to 'geek out' and act like a fan in a way that transgresses society's normal proscriptions against such behavior.

There is also a sense among the fans interviewed that this was their space, one that was created with them in mind:

It's definitely a place where if you aren't a fan you can enjoy it, but the people who get the most out of it are the people who know what they're looking at. And I think that they really had that in mind.. (Violet, 21, American)

While non-fans might visit, and even enjoy the park for the unique craft of the simulation, Violet suggests that those who truly appreciate it are the fans of Harry Potter. This is not so much an appropriation of space by fans, as is discussed in relation to other sites of film tourism or fan pilgrimage (Hills 2002, Brooker 2007, Geraghty 2014), but a sense that they are in a place made for them. This works with the broader sense of communitas present among fans in the park. It is a space to perform fandom, made for fans, and therefore welcoming. 


\section{Conclusion and Future Directions}

How do visitors interpret simulated environments, and what leads them to embrace WWOHP? These are the questions that we have investigated in this study. As media-themed environments prosper, it is important to understand what visitors make of such spaces and why they continue to appeal. Through participatory observation and interviews, we have identified several key themes in the WWOHP fan experience to help understand its attraction.

First, we have shown how the theme park can be seen as a medium. Considering theme parks in this way moves beyond discussion of whether they are positive or negative for society and towards a consideration of what they are as a form. As a medium, the theme park has its own specificity - most notably separation from the 'outer' world and physical interaction with a narrative. In theory, it should be sensorily authentic (Lukas 2007) and provide a spatial and embodied connection to a narrative world (Mitrasinovic 2006, Koren-kuik 2014). This makes the theme park similar to ideas of immersion as found in media studies, where it is seen as a way to make a fictional environment feel "real," whether through technology (Huhtamo 1995) or through the mental process of imagining the world as inhabitable (Ryan 2000, Saler 2012).

It is this concept that WWOHP builds on, and that the fans respond to. For the fans interviewed here, WWOHP is interpreted as an adaptation of the Harry Potter series in its own right, one that uses the medium specificities of the theme park to present a new 
interpretation of the book series. The fans have already mentally inhabited this narrative world through their ironic imagination (Saler 2012), which is extended into the park. The approval of series author J.K. Rowling and the amount and quality of detail from the series found in the park give it a sense of sensory authenticity. Through being there, visitors can gain an embodied understanding of what it would be like if they could actually visit these locations. In doing so, they feel connected not only to the narrative itself, but to their fandom and the other fans inhabiting the space - they are all there for, and in, Harry Potter.

This study also shows that the idea of the 'ironic imagination' is useful when discussing the theme park experience. While Saler speculated that "ironic self-reflexivity may be powerless against physical reflexivity," $(2012,55)$ we can see from the example of WWOHP that even though the physicality makes the environment more real, there are still limits. It is "as if" Diagon Alley is visited, and for all the emotionality of "being there," there is appreciation for, and awareness of, the work put in to making the experience. It is this double consciousness that makes the simulated environment work. The structure and nature of the theme park - that it is a set-aside place of pretending means that is interacted with as a fiction. Not every theme park will embrace this to the same extent as WWOHP, and not every visitor will accept the illusion as believable, but as the industry moves towards more immersive environments, it is important to understand the way that many visitors relate to such spaces.

However, WWOHP does not only suggest a new sort of theme park, it also exemplifies a new relationship between media producers and fandom that needs further attention. By encapsulating the fan in an official version of the Harry Potter world, it also 
absorbs practices that had previously been the domain of fans and brings them back under control. This is most clearly visible in the purchasable merchandise at WWOHP, which draw upon traditions of cosplay and fan creation, but also in the way in which WWOHP has positioned itself as part of fan culture. It hosts a yearly Celebration of Harry Potter event, featuring actors and other creative professionals from the film series, and has worked with fan convention GeekyCon (formerly LeakyCon, a Harry Potter-themed convention) to host a special event that allows convention attendees, for an extra fee, to be admitted to the park after closing time. These events are extremely popular and suggest that, in some way, Universal and Warner Brothers have successfully harnessed fandom.

The fans involved in this study (and it must be noted that these are fans who were already inclined towards appreciating WWOHP) suggest how this relationship works. They were pleased that Universal had put the resources into building the park in a way that meant they could have the desired embodied - and official - connection to the storyworld. That Universal had done so was a sign that their fandom was valuable and valued. They were happy to pay for the experience, which they found meaningful, and reluctant to critique it too heavily. If Henry Jenkins could see fans in 1992 as rebellious poachers, working at a counterpoint to the media industry, fans in the contemporary media environment might better be seen as the game. They are carefully cultivated, valued, and used for resources. This is not to say that 'poaching' as Jenkins described it has disappeared, as it was always focused on the mental processes and imaginative work of fans in interpreting industry products, but that the relationship has changed, at least for highly successful media franchises like Harry Potter. More research is required to 
understand what this means for the future of fandom and, indeed, of audience practices more generally, and how both fans and the media industry adapt to the poacher's domestication.

\section{FUNDING ACKNOWLEDGEMENT}

This work was made possible by a research grant from the Netherlands Organisation for

Scientific Research (GW, PR-11-77)

\section{REFERENCES}

Aden RC (1999) Popular Stories and Promised Lands: Fan Cultures and Symbolic Pilgrimages. Tuscaloosa and London: The University of Alabama Press

Bacon-Smith C (1992) Enterprising Women: Television Fandom and the Creation of Popular Myth. Philadelphia: University of Pennsylvania Press

Balides C (2003) Immersion in the Virtual Ornament: Contemporary "Movie Ride" Films. In Thorburn D and Jenkins H (eds), Rethinking Media Change: The Aesthetics of Transition. Cambridge and London: The MIT Press, pp. 315-336

Baudrillard J (1994) Simulacra and Simulation trans Glaser SF. Ann Arbor: University of Michigan Press.

Beeton S (2005) Film induced tourism. Clevedon: Channel View Publications

Booth P (2015) Playing Fans: Negotiating Fandom and Media in the Digital Age. Iowa City: University of Iowa Press

Booth P and Kelly P (2013) The changing faces of Doctor Who fandom: New fans, new technologies, old practices? Participations 10(1): 56-72

Brooker W (2007) Everywhere and nowhere: Vancouver, fan pilgrimage, and the urban imaginary. International Journal of Cultural Studies 10(4): 423-444 
Bryman A (2004) The Disneyization of Society. London, Thousand Oaks, and New Delhi: Sage

Charmaz K (2006) Constructing Grounded Theory: A Practical Guide Through Qualitative Analysis. London, Thousand Oaks, and New Delhi: Sage

Clavé SA (2007) The Global Theme Park Industry. Wallingford and Cambridge: CABI

Couldry N (200) The Place of Media Power: Pilgrims and witnesses of the media age. London and New York: Routledge

Crouch D (2000) Places around us: embodied lay geographies in leisure and tourism. Leisure Studies 19(2): 63-76

Darley A (2000) Visual Digital Culture: Surface place and spectacle in new media genres. London and New York: Routledge

Davis, SG (1996) The theme park: global industry and cultural form. Media Culture and Society 18(3): 399-422

Eco, U (1986) Travels in Hyperreality: Essays, trans Weaver W. San Diego, New York, and London: Harcourt Brace and Company

Geraghty, L (2014) Cult Collectors: Nostalgia, Fandom, and Collecting Popular Culture. London and New York: Routledge

Gottdiener, M (2001) The Theming of America: Dreams, Media Fantasies, and Themed Environments. Boulder: Westview Press

Grau, O (2003) Virtual Art: From Illusion to Immersion, trans Custance G. Cambridge and London: The MIT Press

Gunelius, S (2008) Harry Potter: The Story of a Global Business Phenomenon. Houndmills and New York: Palgrave Macmillan

Hills, M (2002) Fan Cultures. London and New York: Routledge

Huhtamo, E (1995) Encapsulated bodies in motion: simulators and the quest for total immersion. In Penny S (ed) Critical Issues in Electronic Media, pp. 159-186.

Jenkins, H (1992) Textual Poachers. New York and London: Routledge

Klein, N (1999) Electronic Baroque: Jerde Cities in Bradbury, R (ed) You Are Here. The Jerde Partnership International, London: Phaidon, accessed http://artefact.mi2.hr/a04/lang_en/theory klein_en.htm 
Koren-kuik, Meyrav (2014), Desiring the Tangible: Disneyland, Fandom, and Spatial Immersion. in Barton KM and Lampley JM (eds), Fan CULTure: Essays on Participatory Fandom in the $21^{\text {st }}$ Century. Jefferson and London: McFarland and Company

Lee, C (2012) 'Have Magic, Will Travel': Tourism and Harry Potter's United (Magical) Kingdom. Tourist Studies 12(1): 52-69

Lukas, S (2007) Theming as a Sensory Phenomenon: Discovering the Senses on the Las Vegas Strip. In Lukas, S (ed), The Themed Space: Locating Culture, Nation, and Self. Plymouth: Lexington, pp. 75-95

Mittell, J (2014) Strategies of Storytelling on Transmedia Television. In Ryan ML and Thon JN (eds), Storyworlds Across Media: Towards a Media-Conscious Narratology. Lincoln and London: University of Nebraska Press, pp. 253-277

Mitrasinovic, M (2006) Total Landscape, Theme Parks, and Public Space. Aldershot and Burlington: Ashgate

Murray, JH (1997) Hamlet on the Holodeck: The Future of Narrative in Cyberspace. New York: The Free Press

Niallgirlalmighty (July 23 2014) Tumblr post, http://niallgirlalmighty.tumblr.com/post/9268173743, viewed October 122015

Reijnders, S (2011) Places of the imagination. Media, tourism, culture. Farnham: Ashgate Publishing

Rodaway, P (1994) Sensuous Geographies: Body, sense, and place. New York and London: Routledge

Ryan, ML (2001) Narrative as Virtual Reality: Immersion and Interactivity in Literature and Electronic Media. Baltimore and London: The Johns Hopkins University Press

Saler, M (2012) As-If: Modern Enchantment and the Literary Prehistory of Virtual Reality. New York: Oxford University Press

Sorkin, M (1992) See You in Disneyland. In Sorkin M (ed), Variations on a Theme Park: The New American City and the End of Pubic Space. New York: Hill and Wang, pp. 205249

Turner, Victor (1977) The Ritual Process: Structure and Anti-Structure. Ithica: Cornell Paperbacks 